\title{
INTELECTUAIS \& MILITANTES E AS POSSIBILIDADES DE DIÁLOGO
}

\author{
Maria Ignez S. Paulilo \\ UFSC/Pesquisadora CNPa
}

\begin{abstract}
Resumo: O objetivo do artigo é explicitar o conceito de natureza que dá substrato às ideias e às ações do Movimento de Mulheres Camponesas - MMC, procurando refletir sobre as possibilidades de diálogo entre militantes e intelectuais, levando-se em conta que, enquanto o feminismo acadêmico tem forte influência das correntes desconstrucionistas, as mulheres agricultoras conservam o pressuposto da identificação entre natureza e feminino, tendo por base uma visão profundamente religiosa. Nas possibilidades de diálogo, é levantada a importância de correntes ligadas à sociologia da compreensão.

Palavras-Chave: movimento de mulheres agricultoras; feminismo; gênero; agricultura familiar.
\end{abstract}

\section{Introdução}

Os objetivos deste artigo podem ser assim resumidos: a) a partir de uma breve revisão histórica dos conceitos de natureza, mostrar que são construções que variam no tempo e no espaço e em diferentes grupos sociais; b) perceber, então, qual são as construções do mundo natural que embasam as ideias e ações do Movimento de Mulheres Camponesa MMC frente às/aos pesquisadoras/es acadêmicas/os ligadas/os ao feminismo; e c) diante da presença de diferenças na forma de entender o mundo humano e não humano, procurar construir pontes para um diálogo sem preconceitos.

Para quem tem acompanhado o Movimento de Mulheres Camponesas (antigo MMTR - Movimento de Mulheres Trabalhadoras Rurais) no Sul do Brasil, a crescente preocupação com a alimentação saudável e a soberania alimentar nos últimos anos é indiscutível. Segundo documento distribuído no ano de 2004, ano em que vários movimentos autônomos de mulheres existentes no Brasil se reuniram em Brasília e decidiram formar uma única organização, o MMC, abrangendo 16 Estados brasileiros, 'temos uma recuperação das

Copyright @ 2010 by Revista Estudos Feministas.

1 Embora o MMC tenha grande abrangência e fale em nome das mulheres agricultoras do Brasil, há no Nordeste um conjunto de movimentos autônomos que não aderiram à proposta unificadora apresentada em 2004 e permaneceram formando o Movimento de Trabalhadoras Rurais do Nordeste - MMTR-NE. Segundo Caroline Araújo Bordalo, no Brasil "atualmente existem duas articulação de mulheres 'independentes', o MMTR-NE e o MMC". A autora faz uma análise interessante das diferentes forças, instituições e motivações que formaram as duas organizações (ver BORDALO, 2007, p. 5). Diante disso, é preciso ficar claro que estamos falando neste artigo apenas sobre o MMC, mais bem consolidado no Sul do país. 
várias bandeiras defendidas, muitas conquistadas ao longo de 21 anos, ou seja, desde o surgimento do Movimento de Mulheres Agricultoras em Santa Catarina em 1983, posteriormente articulado com o MMTR em 1995 e, desde 2004, fazendo parte do MMC que está filiado à Via Campesina. ${ }^{2}$

A história de luta do MMA/SC, marcada pela existência das mulheres agricultoras organizadas, abrange a conquista de sair de casa e pensar sobre o seu destino, o reconhecimento da Profissão de Trabalhadora Rural, a formação e capacitação das dirigentes e das mulheres sobre seus direitos, as lutas pelo direito à Saúde Pública e de qualidade, o acesso aos direitos previdenciários (aposentadoria, auxílio doença, auxílio acidente de trabalho, auxílio invalidez, pensão de viúva/o e salário maternidade, e a luta por um novo projeto de agricultura agroecológica que recupere as sementes crioulas e a sabedoria popular, buscando a preservação da biodiversidade. ${ }^{3}$

A preocupação das agricultoras com a agroecologia faz com que o movimento a que pertencem possa ser considerado uma corrente dos movimentos ecofeministas, mesmo que este não seja um termo usualmnte utilizado pelas militantes. Em apoio a essa afirmação, temos o conceito de ecofeminismo elaborado por Maria Luisa Femenías e citado por Maria Cristina Spadaro e Maria Luisa Femenías:

Es decir que, la manera em que se trata al medioambiente se relaciona fuertemente com la manera em que se piensa y se trata a las mujeres. Así el feminismo ecológico tiene sus raíces em uma amplia variedad de corrientes feministas (liberal, marxista, radical, socialista, feminismo negro o de tercer mundo), pero lo que distingue es su insistência em que la naturaleza no-humana es um assunto feminista. Em efecto, al extender las críticas proprias del feminismo a la naturaleza, permite compreender el solapamiento y el entrecruzamiento de todos los modos de dominación. ${ }^{4}$

Ao dizermos que o que caracteriza o ecofeminismo é o pressuposto de que a natureza não humana é um assunto feminista, poder-se-ia perguntar se o MMC se considera ou pode ser considerado um movimento feminista. Devido a uma 'marca de origem' do movimento feminista como algo ligado às mulheres brancas ocidentais de classe média, há reserva por parte de participantes de movimentos populares de se declararem feministas. Porém, em um encontro recente do MMC realizado em Xaxim-SC, nos dias 21 a 23 agosto de 2010, o tema foi "Mulher Camponesa e Feminismo". Percebe-se, portanto, uma aproximação desse movimento com os ideais feministas, embora tenha ficado claro que isso ainda incomodava mulheres da base do movimento. Quanto ao termo "ecofeminista", houve rejeição inclusive pela liderança.

Apesar da grande diversidade de posturas que o termo feminismo abrange, podese, ao menos, tirar um denominador comum que é a crença na importância das mulheres na transformação de um mundo que as trata como seres inferiores. Nesse sentido, o MMC pode ser considerado, sim, como feminista, enquanto sua preocupação com o meio ambiente permite que o ecofeminismo possa ser visto pelo menos como uma de suas facetas.

\footnotetext{
${ }^{2}$ Esta organização constitui-se em maio de 1993, durante a Primeira Conferência da Via Campesina realizada na Bélgica. A segunda conferência aconteceu em 1996, no México; a terceira, em 2000, na Índia; e a quarta em 2004, em São Paulo. A Via Campesina é uma organização internacional que procura desenvolver a solidariedade e unidade entre organizacões camponesas, trabalhadores agrícolas, mulheres rurais $e$ comunidades indígenas e negras da Ásia, África, América e Europa. Tem entre seus principais objetivos a defesa da soberania alimentar, ou seja, do direito dos povos de decidir sobre sua política agrícola e alimentar (www.viacampesina.org).

${ }^{3}$ MMC, 2004

${ }^{4}$ FEMENÍAS E SPADARO, 2004, p. 233.
} 
Quando se fala em ecofeminismo e suas várias correntes, um ponto tem importância central: em comparação com os homens, estariam as mulheres mais próximas da natureza? As respostas afirmativas e negativas a essa pergunta têm levado a debates intensos. Há pensadoras como Vandana Shiva e Maria Mies ${ }^{5}$ que são mundialmente conhecidas pela defesa da ideia de que mulheres e natureza têm uma ligação essencial, ao passo que um número bastante significativo de feministas não só negam essa ligação, como temem que a crença em um vínculo, tido como inato, possa reforçar as já tão presentes ideias discriminatórias sobre a inferioridade intelectual das mulheres. Para as feministas que respondem negativamente à pergunta feita, o que é considerado feminino pela sociedade é uma construção social legitimadora da dominação entre os sexos. Para estas últimas, as primeiras seriam "essencialistas" no sentido de acreditarem em uma "essência feminina" imutável. ${ }^{6}$

É interessante como neste binômio mulher/natureza, as correntes que veem a mulher, bem como o homem, como sendo, em maior ou menor grau, uma construção social, elaboram variados níveis de desconstrução do que é tido como feminino ou masculino, chegando até a posturas bastante radicais como a teoria queer de Judith Buttler, segundo a qual não só o gênero, mas o próprio sexo é construído. Para essa autora, a representação do que deve ser entendido como matéria (natureza, corpo, sujeito etc.) é anterior à matéria mesma porque o que a regulamenta é o discurso que a constrói que, além disso, naturaliza essa construção. ${ }^{7}$ Porém, a ideia de natureza é menos discutida. O que é a natureza? Ora ela é vista como imutável em suas leis de funcionamento mais profundas e, ao mesmo tempo, como 'sábia', ou seja, devemos seguir o que nos parece ser suas indicações; ora ela é vista como estando à disposição do homem, de sua ciência e de sua técnica. Os defensores das duas concepções veem seu entendimento como sendo o 'verdadeiro'.

Basta, porém, uma pequena reconstituição histórica sobre as diferentes filosofias da natureza que regeram o entendimento do que é 'natural', ao longo dos séculos, para que toda essa certeza se desmanche.

\section{Há algo de natural na natureza?}

Iniciando com Aristóteles (384 a. C.-322 a. C.), vemos que, para ele, a natureza é um princípio e uma causa. É princípio em relação aos fenômenos que são autodeterminados e voltados à preservação e/ou reprodução, portanto, há aqui uma ideia de acabamento, de autossuficiência, de perfeição mesmo, ideia que não está presente no que ele considera como produtos da técnica. Enquanto causa, ela só o é quanto aos tipos de mudança que levam um ente à sua completude. Como é a noção de acabamento, de completude que ocupa lugar central na filosofia da natureza de Aristóteles, de tal modo que um ente natural e sua forma são idênticos, a tendência à preservação e à persistência daí decorrentes traz em seu cerne a ideia de 'essência', daquilo que permanece e define a coisa. ${ }^{8}$ Dessa noção deriva o termo 'essencialista' para descrever qualquer conceito que tenha por base algo considerado 'natural' no sentido de 'imutável', permanente.

O filósofo Luc Ferry torna essa ideia de completude mais clara quando diz que, para entendermos o que é cosmos entre os filósofos gregos, "o mais simples é imaginar o todo do universo como se fosse um ser organizado e animado". "' ́ a esta estrutura ordenada que chamam de "divino" (theion), um divino que "não tem nada de um Deus pessoal, mas que

${ }^{5}$ SHIVA e MIES, 1997

${ }^{\circ}$ PAULILO, 2007.

7 FEMÍNIAS; SPADARO, 2004, p. 237.

${ }^{8}$ ANGIONI, 2004, p. 6.

9 FERRY, 2007, p. 38-39, grifos do autor. 
se confunde com a ordem do mundo". Não há um Ser exterior ao universo como advogam os judeus ou os cristãos. A ideia da presença de um Deus criador de tudo que existe vem com a conquista da hegemonia religiosa pelo cristianismo na Europa.

Na alta ldade Média, a natureza é para ser contemplada e não explicada. ${ }^{10} \mathrm{Como}$ diz o filósofo Hugo de Saint-Victor (1096-1 141), "a exemplo da Escritura, a natureza constitui um livro escrito pelo dedo de Deus"." Essa perspectiva deriva da concepção de que o cosmo se reveste de um caráter sagrado, ou seja, a natureza é expressão direta da vontade divina. ${ }^{12} \mathrm{~A}$ terra ainda é vista como o centro do universo como afirmara, centenas de anos antes, Ptolomeu (90-168). Porém, entre os séculos XII e XIII, devido a um novo contexto econômico e político, começam a surgir, principalmente na Itália meridional e Espanha, traduções de textos gregos e árabes, produzidos antes da tradição religiosa cristã ou fora dela. Em um século são traduzidos textos sobre física, astronomia, alquimia e magia que revelam a riqueza do pensamento aristotélico, helenístico e árabe, permitindo o surgimento de um contexto favorável a ideias mais racionais, entre elas a de uma natureza fora da esfera do sagrado. O filósofo inglês Adelardo de Barth (1080-1152) recupera dos pensadores árabes a ideia de 'razão' que se opõe ao estabelecimento de uma relação direta entre fenômenos naturais e vontade de Deus. Inicia-se, assim, uma busca pelas causas desses fenômenos, desvinculada da tradição religiosa.

A visão aristotélica-ptolomaica de mundo perdura até o século XVII, quando ocorrem grandes transformações no pensamento ocidental. Para Luc Ferry, a Europa assiste em menos de cento e cinquenta anos, durante os séculos XVI e XVII, a uma revolução científica sem precedentes na história da humanidade, que trouxe uma ruptura cultural profunda e radical. ${ }^{13}$ Entre as obras que contribuíram para a consolidação de uma nova visão de mundo está a publicação das teses de Galileu Galilei, Diálogos sobre os dois principais sistemas de mundo, em 1632. Albertino L. Gallina afirma que Galileu mostrou grande persistência na construção de uma ciência que tornasse possível o conhecimento racional da natureza, daí derivando seus desentendimentos com a Inquisição que não admitia que se duvidadasse dos dogmas religiosos. ${ }^{14}$ Para ele, esse conhecimento só seria acessível através da linguagem matemática. Porém, segundo o mesmo autor, quem na verdade conseguiu encontrar as bases do conhecimento que permitiram à matemática fundamentar um discurso sobre a natureza foi Descartes.

O filósofo, físico e matemático francês René Descartes (1596-1650) vê a natureza como uma grande máquina que pode ser reduzida a quantidades. Considera o mundo material e, portanto, os corpos em geral, como máquinas, concepção na qual não restam mais resquícios de um poder intrínseco às coisas, como acontece na ideia de essência de Aristóteles. Para se explicar os acontecimentos no mundo físico há necessidade de princípios que devem ser externos aos próprios corpos envolvidos. Não importam mais as causas, mas as leis que regem o funcionamento do universo. Para que se compreenda melhor o sentido do que se considera o "mecanicismo cartesiano" é preciso, antes de criticá-lo com os olhos de hoje, entender o quanto de maravilhoso era atribuído às máquinas pelos olhos admirados dos europeus do séc. XVII. ${ }^{15}$ Talvez fosse melhor dizer mais que "admirados" e, sim, "estarrecidos" porque, como diz Luc Ferry, na medida em que a física moderna começou a

\footnotetext{
${ }^{10}$ Noeli Dutra ROSSATTO, 2004

1 SAINT-VICTOR apud Jacques LE GOFF e Jean-Claude SCHMITT, 2006, p. 263, grifos dos autores.

${ }^{13}$ SAINT-VICTOR apud LE GOFF e SCHMITT, 2006, p. 264.

14 FERRY, 2007, p. 116.

${ }^{15}$ GALLINA, 2004, p. 31

16 GALLINA, 2004, p. 28-37.
} 
se desenvolver, colocou em questão todos os princípios da religião cristã. ${ }^{16} \mathrm{O}$ universo perde sua harmonia de cosmos e a humanidade se depara com o caos.

Para reencontrar alguma coerência, algum sentido no mundo, foi preciso, de acordo com Ferry, que "o próprio ser humano, no caso, o sábio, introduza a ordem nesse universo que, à primeira vista, não oferece nenhuma". ${ }^{17}$ Ainda segundo o mesmo autor, a filosofia moderna se mostra à altura desse desafio com o surgimento da Crítica da razão pura, de Kant. ${ }^{18}$ Entramos assim na era do "humanismo", ou seja, na era em que o homem se encontra só. ${ }^{19}$ É o homem que está no centro do conhecimento e, por isso, Kant não tem uma filosofia da natureza, mas uma filosofia do conhecimento da natureza. Para ele, se a natureza significasse existência das coisas em si mesmas, não poderíamos conhecê-la nem a priori nem a posteriori. ${ }^{20}$

'Humanismo', porém, não significa 'humanidade', mas 'homem'. As mulheres ainda vão esperar muito tempo antes que os movimentos feministas comecem a lutar para incluílas em igualdade de condições no mundo dos 'seres humanos'. Segundo o filósofo Roberto Romano, em seu livro Lux in Tenebris: meditações sobre filosofia e cultura, "o mesmo Kant, que defendeu a saída corajosa da humanidade de seu estado infantil, menor, mantém este último para a mulher". ${ }^{21}$ Para comprovar o que diz, cita um trecho onde o filósofo do séc. XVIII define o estatuto da mulher na sociedade:

Para a [...] indissociabilidade de uma união, o encontro ocasional de duas pessoas não basta; um elemento deve ser submetido ao outro, e, reciprocamente, este deve ser superior para poder comandar e governar [...] o homem deve ser superior à mulher pela força corporal e coragem, a mulher, pela faculdade natural de submeter-se à inclinação que o homem tem por ela, para dominá-la. ${ }^{22}$

Kant não está sozinho entre os grandes filósofos que destacam a inferioridade das mulheres. Entre muitos outros como Platão, Kierkegaard e Schopenhauer, temos Hegel (17701831), que na sua Filosofia do Direito diz:

As mulheres [...] podem ser cultivadas, mas não foram feitas para as ciências nobres, nem para a filosofia, nem para certas formas artísticas, que exigem o universal. As mulheres podem ter pensamento, gosto, elegância, mas o ldeal não lhes é acessível [...] Se as mulheres estão no ápice do governo, o Estado corre perigo, pois elas não agem segundo as exigências do Universal mas segundo inclinações e opiniões contingentes $[\ldots]$.

Se a mulher está distante do "Ideal" e do "Universal", como poderia estar em igualdade de condições dentro de grandes conceitos como 'Homem', 'Humanidade' e 'Humanismo'? A doutora em filosofia Rosa Maria Rodríguez Magda $^{24}$ estende a crítica a filósofos mais recentes, começando pela clara e reconhecida misogenia de Nietzsche e incluindo, em sua crítica, autores considerados pós-modernos, referindo-se a uma ausência de estudos sobre a mulher na História da Sexualidade de Foucault (embora ressalte a importância desse autor para o pensamento feminista), ao 'esquecimento' da diferença

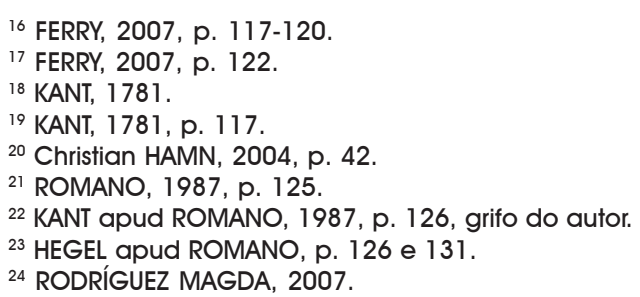


sexual na noção de corpo em Deleuze, ao uso que Baudrillard faz do 'feminino' como puro artifício a partir de uma ritualidade masculina e por aí vai.

Voltando ao conceito de natureza, uma reconstituição agora não mais por pensadores, mas por épocas, reforça seu caráter transitório.

Ao reconstituir o conceito de natureza na história do pensamento ocidental, Thomas Kesselring ${ }^{25}$ identifica cinco fases distintas: Antiguidade grega; Idade Média; primeira fase da Modernidade; segunda fase da Modernidade (séc. XIX e início do séc. XX) e últimas décadas do século XX. Apesar da diversidade de conceitos e ideias encontrados, o autor afirma que essa diversidade seria ainda bem maior se fossem levadas em conta as concepções orientais e as culturas indígenas:

[...] a Natureza inteira foi igualada ao âmbito da criação: nela manifestam-se a bondade e a sabedoria divinas [...]. O conceito de natureza adquiriu assim um componente normativo [...]. Sem essa implicação normativa no conceito medieval de Natureza, a discussão sobre o direito natural no começo da idade média [...] permaneceria incompreensível. E sem a ideia de direito natural não haveria a ideia moderna dos direitos humanos, isso é, direitos que competem, por natureza, a cada ser humano. ${ }^{26}$

Essa belíssima passagem de Kesselring, que começa no cristianismo da Idade Média e vem até os direitos humanos, permite-nos compreender porque a concepção religiosa da natureza foi tão fecunda para os movimentos sociais que buscam não só igualdade, mas também equidade para mulheres e homens, ricos e pobres, humanidade e natureza. Porque a natureza, além de divina, é normativa, contendo, embutida na forma de entendê-la, tanto a igualdade entre todas as criações de Deus quanto seu direito de existir e, portanto, de serem respeitadas, amadas e protegidas. Como consequência, essa visão traz a norma de que nós, humanos, temos obrigação de vermos a equidade como 'um direito natural', enquanto derivado da 'natureza' que é divina, uma obra de Deus.

Somente uma sociedade perfeita e, portanto, utópica poderia contemplar a tudo e a todos de maneira a que nada de essencial lhes faltasse, seja material, como alimentos, roupas e moradia, seja imaterial, como respeito, espiritualidade e solidariedade. Vê-se a confirmação dessa utopia nas palavras de Allie van der Schaaf que, estudando a busca por direitos sociais e igualdade de gênero no Movimento de Mulheres Agricultoras do Rio Grande do Sul, diz:

O movimento anseia por uma sociedade utópica de "leite e mel", inspirada na Teologia da Libertação, ${ }^{27}$ e combina isso com elementos do feminismo teológico. [...] Para recuperar a sociedade de 'leite e mel', seria necessário lutar contra o capitalismo/ neoliberalismo [...] reintroduzindo os valores essenciais na vida humana, tais como a dignidade, a igualdade, a solidariedade, a justiça e o prazer, através de uma vivência religiosa espiritual. As mulheres trabalhadoras rurais teriam um papel primordial nessa recuperação da "vida", sendo as parceiras da fertilidade, tanto dos seres humanos quanto da terra.

25 KESSELRING, 2000

${ }^{26}$ KESSELRING, 2000, p. 158, grifos do autor.

${ }^{27}$ A Teologia da Libertação é uma corrente teológica que reúne diversas igrejas cristãs e foi desenvolvida no Terceiro Mundo e na periferia dos países ricos a partir dos anos 1970. Está baseada na opção pelos pobres e apoia-os na luta contra a pobreza e contra o desrespeito aos direitos sociais. Desenvolveu-se inicialmente na América Latina e, na busca de uma visão das desigualdades à luz da fé cristã, recebe influência das Ciências Sociais e, em especial, de algumas correntes marxistas.

${ }^{28}$ SCHAAF, 2001, p. 164 
Schaaf permite assim compreender a simbologia contida na presença, em um encontro de mulheres rurais ligadas aos movimentos sociais, de uma agricultora grávida que trazia seu ventre fertilizado coberto por sementes coladas. A fala de D. Adélia Schmitz, uma das líderes nacionais do MMC, também reforça a ligação entre mulheres, vida e natureza:

[...] porque a monocultura mata a biodiversidade; debaixo de um matagal de eucalipto nem as formigas se criam, mata a terra! Mata a vida! Porque a terra possui vida. Nem uma abelha, nada vai nessas árvores, e a biodiversidade onde é que fica? A quantidade de água que esses eucaliptos absorvem da terra! As mulheres defendem a vida e querem que as futuras gerações também tenham condições dignas de viver. A função social da terra é produzir comida.

Mas não só as agricultoras identificam o ato de plantar, colher e dar à luz novos seres humanos como um dos principais esteios da sobrevivência do planeta Terra, identificando assim a mulher com uma natureza normativa que tem como fundamento a igualdade e o livre acesso aos direitos humanos.

O obstetra francês Michel Odent, bastante conhecido e reconhecido, em seu livro The Famer and the Obstetrician ( $O$ camponês e a parteira), ${ }^{30}$ faz uma associação vital entre o ato de plantar e o de gerar, traçando um paralelo entre a industrialização da agricultura e a industrialização do parto, quando afirma que a principal diferença entre esses dois processos é que desastres como a doença da vaca louca, a disseminação da febre aftosa entre os rebanhos e o uso indiscriminado de agrotóxicos têm alertado a humanidade para os riscos com relação à produção de alimentos. Porém, essa mesma humanidade, segundo Odent, está ainda adormecida com relação aos perigos da intervenção das novas tecnologias médicas durante o trabalho de parto das mulheres. Lendo o depoimento da ecofeminista Vandana Shiva ${ }^{31}$ sobre o momento em que abandona a sala de parto de um hospital, cujos médicos queriam submetê-la a uma cesariana, e procura outra instituição de saúde que lhe permitiu ter um parto normal, vemos semelhança entre esses dois pensadores de formação e culturas diversas.

Apesar da contribuição positiva que a associação entre mulher e natureza tem trazido para a luta por igualdade e direitos, há sempre nela o risco de reforçarmos uma visão que, ao colocar a mulher em um plano mais próximo do mundo natural, inferioriza-a porque os que o fazem não atribuem à natureza uma origem divina mas, sim, entendem-na como objeto da ação e da dominação dos homens:

[...] o próprio homem, cujo lugar, durante a Idade Média, estava situado dentro da natureza - como essa, o Homem teria sido criado por Deus -, começou a assumir uma posição externa à natureza, uma posição quase divina. Ele abandona a sua menoridade e eleva-se como dono da natureza, como seu dominador. A natureza que, antes, era o âmbito da criação, torna-se objeto dele: objeto de sua ciência e da sua manipulação. ${ }^{32}$

${ }^{29}$ Entrevista concedida a Maria Ignez Paulilo por Adélia SCHMITZ em 2007. Durante um debate, meu colega Prof. Dr. David J. Caume fez uma observação interessante, dizendo que, do mesmo modo que se pode ler esta citação como tendo um substrato religioso, podemos lê-la como uma manifestação política. Não discordamos, pois o religioso e o político se entrelaçam profundamente nos movimentos que se originaram no bojo da Teologia da Libertação. Segundo Carlos SELL, 2004, esta teologia é permeável a diferentes correntes críticas da sociedade atual. Tendo seu solo na tradição católica é, como tal, crítica da modernidade. Apoia-se também na tradição marxista e, nesse sentido, é moderna. Por ter incorporado tradições místicas e ecológicas, tem seu lado pós-moderno.

30 ODENT, 2002

31 SHIVA, 1997.

32 KESSELRING, 2000, p. 161. 
Thomas Kesselring expõe com maestria o momento em que homem separa a natureza, a razão humana e o mundo físico. Há somente um reparo a fazer: o homem separou-se sozinho da natureza, deixando a mulher junto a ela. O termo "Homem", escrito com a inicial maiúscula como o faz o autor, deveria significar a Humanidade, porém, como já dissemos e como tão bem denunciam as feministas, nele está contido apenas o masculino. Então, quando se identifica mulher e natureza podemos tanto estar falando de uma natureza divinizada como de uma natureza rebaixada ao mundo físico, ao lado animal do homem. É este segundo conceito que afasta inclusive feministas cristãs dessa identificação. Ivone Gebara, uma das primeiras teólogas ecofeministas do Brasil, é clara quando diz:

Então o ecofeminismo, ou pelo menos o ecofeminismo com o qual eu trabalho, não quer, de forma alguma, acentuar a ligação da mulher com a natureza, mas justamente quer denunciar essa acentuação que vem de um sistema patriarcal racionalista que aproxima o macho masculino da razão e o feminino da natureza como se fôssemos produtos inferiores. E foi esta aproximação que criou distorções filosóficas, antropológicas e, evidentemente, distorções sociais.

Do contato constante que mantemos com as militantes do MMC, podemos ver que sua postura crítica, resultante da vivência que elas têm enquanto agricultoras, da destruição que sofre o meio ambiente e do perigo dos agrotóxicos, é reforçada pela ideia religiosa tradicional de uma ligação forte entre mulheres e natureza. Digo "religiosa" porque sua crença não vem da leitura das feministas essencialistas como Vandana Shiva, mas sim do fato de as agricultoras verem a vida e a natureza como "dons de Deus", pois quase todas começaram sua militância junto à igreja. Digo "tradicional" porque não incorpora as críticas de Ivone Gebara.

Comparando as visões de natureza dos filósofos que consideram a mulher inferior ao homem por estar mais próxima do mundo 'animal' ou 'selvagem', enfim, do mundo 'instintivo', e a concepção religiosa da natureza que defendem as agricultoras, percebese, claramente, a razão da diferença. Se para os primeiros aproximar-se do mundo não humano é 'inferiorizar-se', para as segundas é 'elevar-se', aproximando-se da perfeição da natureza enquanto obra de Deus. Não é só a visão de mulher que muda, mas também a de natureza: por isso foi necessário, neste texto, dedicar tanto espaço para mostrar as diferentes concepções humanas sobre o mundo não humano.

Um novo alento que reforça a visão de mulher ligada à natureza surgiu com as políticas públicas que enfatizam o papel feminino tradicional. Podemos falar sem susto de duas delas: o Programa Bolsa Família (PBF) e o apoio dado a projetos de produção orgânica, sementes crioulas, ervas medicinais e alimentação saudável. Dessas duas iniciativas, a mais consolidada e facilmente visível é o PBF. Esse programa será, portanto, aqui tomado como exemplo.

Ao estudarem políticas públicas de combate à pobreza em Londrina, Silvana A. Mariano e Cássia M. Carloto chegam a conclusões válidas para o país todo. Segundo as autoras, o PBF, devido à prevalência de a titularidade do benefício recair sobre as mulheresmães, "desenvolve mecanismos que reforçam a tradicional associação da mulher com a maternidade e as tarefas pertencentes à clássica esfera reprodutiva". ${ }^{34} \mathrm{E}$ dizem mais ao afirmar que programas assim "atuam para converter em termos equivalentes categorias

${ }^{33}$ GEBARA apud LÓPEZ, 2001, 79-80

${ }^{34}$ MARIANO E CARLOTO, 2009, p. 902 
como 'mulher' e 'mãe'. A estratégia de inclusão e de interpelação das mulheres supõe a seguinte operação ideológica: mulher = mãe ou família=mãe". ${ }^{35}$

Se tradicionalmente a associação entre mulher e maternidade servia para confinar as esposas ao lar e torná-las dependentes financeiramente dos maridos, não se pode ignorar o surgimento de algo novo: a importância de políticas públicas que beneficiam as mulheres pelo fato de serem mães.

Pelo que foi dito, pode-se ver que não basta que os movimentos feministas discordem da desigualdade entre homens e mulheres e queiram superá-la para que suas visões de mundo sejam compatíveis. Enquanto, para alguns, a categoria "mulher" é algo dado, é um invariante, ou seja, todas as mulheres possuem algo inato que não varia nem ao longo da história, nem em diferentes culturas; para outros, temos que levar em conta de que mulher estamos falando. O risco maior para a luta por mais equidade de gênero não é a existência de diferenças, mas a de que essas diferenças impossibilitem um diálogo.

Neste artigo, nossa preocupação maior é com a possibilidade de diálogo entre pesquisadoras/es e pesquisadas/os e, nesse sentido, fomos buscar inspiração e fundamentos em algumas vertentes da sociologia compreensiva.

\section{Desconstrução, construção e bandeiras de luta}

Enquanto pesquisadora e, ao mesmo tempo, feminista militante, devemos confessar certo desconforto que sentíamos pelo fato de que as firmes convicções essencialistas das participantes do MMC não encontravam ressonância nas nossas próprias convicções, estas muito mais próximas das ideias desconstrutivistas. Enquanto envolvida pelos mesmos ideais de igualdade e preservação da natureza defendidos pelas agricultoras, pensávamos que uma crença que lhes trouxesse mais entusiasmo só poderia nos levar a concordar com ela. Mas, e o nosso lado enquanto pesquisadora? Como nos colocar epistemologicamente diante do que considerávamos um impasse? Claro está que nenhum impasse existiria se acreditássemos ser suficiente "deixar os oprimidos falarem", postura que foi bastante aceita na década de 1980, considerada a década dos movimentos sociais, mas que hoje recebe críticas bem fundamentadas. ${ }^{36}$

Quando falamos de desconstrucionismo, concordamos com Linda M. G. Zerilli, ${ }^{37}$ que diz não se tratar de abandonar a categoria "mulher", mas de trabalhar com uma ideia de "mulheres", cujo comportamento deriva mais de suas experiências de vida que de uma "essência feminina". Perceber a pluralidade onde se via apenas singularidade foi uma conquista do próprio feminismo e não da crítica a ele:

Si ya no consideramos a las mujeres como um grupo com interesses comunes basado en una identidade común, no creo que ello deba atribuirse exclusiva e ni siquiera primordialmente a los considerables embates críticos de pensadoras de la tercera ola como Judith Butler, Chantal Mouffe o Joan Scott. [...] el derrumbre de la categoria mujeres como grupo coherente puede atribuírsele al feminismo propriamente dicho, porque el feminismo es un movimiento político que há aspirado a unir a las mujeres en la

\footnotetext{
${ }^{35}$ Embora se possa discordar da incorporação de uma visão tradicional da mulher nas políticas públicas, não se pode negar o papel que tem tido o PBF na diminuição da pobreza. Segundo Steven M. HELFAND e Mauro E. DEL ROSSI (2008), enquanto para o meio rural brasileiro o desempenho da agricultura no período analisado, 1995-2006, explica cerca de $16 \%$ da diminuição da pobreza, o PBF explica 19\% dessa redução. Nós, feministas, não queremos retirar benefícios que melhorem as difíceis condições de vida das mulheres pobres, mas sonhamos com o dia em que os homens se incumbam dos filhos e idosos tanto quanto elas.

${ }^{36}$ Ver, entre outros, Ruth CARDOSO, 1986

${ }^{37}$ ZERILLI, 2008.
} 
lucha por la liberdad precisamente refutando esa feminilidad naturalisada en la que se basa la ilusión de una identidad común a todas. Em vez de destuir voluntariamente la categoría mujeres como tal, pensadoras como Butler, Mouffe e Scott han tratado de esclarecer - em términos profundamente críticos y para nada nostálgicos - las consecuencias políticas de esa perdida histórica para el futuro del feminismo. ${ }^{38}$

Segundo ainda a mesma autora, não é porque uma tradição chega ao fim que os conceitos tradicionais deixam de ter poder sobre nós. Ao contrário, "pueden volverse todavia más tirânicos por el solo hecho de que uma orientación moral y política confusa resulta más atractiva que la absoluta falta de orientación".$^{39}$ O perigo de uma "orientação confusa", muitas vezes, é dar uma falsa impressão de homogeneidade, de consenso, levando a que pouco se dialogue e que, diante de desentendimentos não esclarecidos, a primeira reação seja a de ruptura e de acusações recíprocas. As acusações mais comuns são as de "autoritarismo" por parte de um grupo, frente ao de "atraso político" ou "tradicionalismo" por parte do grupo oponente.

Como, então, nos prepararmos para o diálogo? Aos poucos (e não sem dores de parto) fomos saindo do impasse e os autores que mais nos inspiraram foram: Bina Argawal, Joan Scott, Clifford Geertz e Giddens. Embora já os conhecêssemos, alguns até bem, não os tínhamos colocado juntos frente a uma situação concreta de pesquisa.

A ideia de uma ecologia do cotidiano foi trazida por Argawal. ${ }^{40}$ Ela estudou várias regiões da Índia e mostrou a relação entre a defesa da preservação das florestas e o cotidiano das famílias rurais pobres, cuja sobrevivência depende, em muito, do que coletam nessas áreas não agriculturadas. Nessa mesma linha, temos o livro editado por Patrícia L. Howard $^{41}$ que revela, através de pesquisas de campo, a grande importância das florestas, mesmo quando se restringem a pequenas áreas preservadas ou mesmo abandonadas, para a obtenção do alimento diário entre famílias pobres do mundo todo, inclusive das que vivem em países ricos como os Estados Unidos. A quantidade e a densidade dos dados apresentados por esses dois trabalhos reforçam a ideia de que o meio ambiente é sim um assunto de mulheres como defendem as ecofeministas. Porém, nessas duas obras, o que aparece é a defesa do meio ambiente enquanto resultado de necessidades imediatas, tais como a fome e a busca da cura através das ervas medicinais. Não há preocupação com a esfera mais mística, espiritual, da relação com a natureza, aspecto que Iraildes $C$. Torres ${ }^{44}$ ressalta ao estudar mulheres dedicadas à lavoura e à pesca na Amazônia.

De maneira semelhante a Bina Argawal, Iraildes Torres também afirma que as mulheres têm uma relação menos destrutiva e de maior zelo com o meio ambiente porque dependem dele em seu cotidiano para alimentar a família. Mas, além disso, ressalta a importância das crenças e dos mitos enquanto mediadores dessa relação, sem desprezar seu caráter normativo. Isso atribui à religiosidade indígena, muito presente nas populações por ela estudadas, a mesma função de fonte de normas e valores que vimos na noção cristã de natureza:

Nas comunidades tradicionais da Amazônia, as fundações de vida e de morte, as ações do cotidiano, o trabalho e as relações sociais são recortadas pelo simbolismo. Homens e mulheres pautam suas relações com a natureza dadivosa em valores mitológicos, sem perder de vista as leis do Estado nacional. Na fala [... de uma

${ }^{38}$ ZERILLI, 2008, p. 14.

${ }^{39}$ ZERILLI, 2008, p. 15-16.

${ }^{40}$ ARGAWAL, 1994.

${ }^{41}$ HOWARD, 2003.

42 TORRES, 2009.

936 Estudos Feministas, Florianópolis, 16(3): 927-940, setembro-dezembro/2010 
entrevistada] aparece tanto a preocupação com a Lei do Defeso, que proíbe a pesca no período da reprodução dos peixes, quanto com a mãe d'água, que exerce poderes sobrenaturais reorientando a vida dentro dos rios. [...]. O mito tem funções normativas e consultivas, fazendo rodar o triângulo homem-mulher/natureza/sociedade numa relação de interdependência. ${ }^{43}$

Se as religiões, sejam indígenas, hindus ou ocidentais, encontram-se nas raízes da maneira como homens e mulheres veem o mundo e a natureza, isso não significa homogeneidade entre pessoas de igual crença. Se as mulheres cuidam da natureza de maneira diferente de como o fazem os homens, as pesquisas mostram que essa diferença é resultado da vivência de cada um, da sua experiência cotidiana, o que nos remete às considerações teóricas de Joan Scott. ${ }^{44}$

Scott, em seu texto "Experiência", trouxe-nos a ideia de que "não são os indivíduos que têm experiência, mas os sujeitos é que são constituídos através da experiência". ${ }^{45}$ Para Scott, não há um ponto de chegada predeterminado; a experiência vai constituindo as identidades e visões de mundo que, como mostra a história, estão em constante mutação. Como os grupos sociais, entre eles as mulheres, formam suas identidades, que nunca são fixas, relaciona-se com o que estão vivenciando no momento. O trabalho de Scott reforça a necessidade de aproximação com as correntes da hermenêutica, no sentido da importância da 'compreensão' enquanto elemento fundamental de inteligibilidade das práticas sociais. Mais ainda porque, como vimos, essas experiências são mediadas por fortes componentes religiosos; religiosidade que, na maioria das vezes, não faz parte das crenças de quem está pesquisando.

Clifford Geertz e Anthony Giddens alertam os pesquisadores para que não se iludam quanto à sua identificação com o grupo estudado, por mais simpatia que tenham pelas ideias de que seus participantes são portadores. Em O saber local, ${ }^{46} \mathrm{Geertz}$ diferencia a "experiência próxima" da "experiência distante". Ele desconfia da possibilidade do investigador de colocar-se "debaixo da pele do outro" e diz:

Para captar conceitos que, para outras pessoas, são de experiência próxima, e fazê-lo de uma forma tão eficaz que nos permita estabelecer uma conexão esclarecedora com os conceitos de experiência distante criados por teóricos para captar os elementos mais gerais da vida social, é, sem dúvida, uma tarefa tão delicada, embora um pouco menos misteriosa, que colocar-se 'embaixo da pele do outro'. O truque é não se deixar envolver por nenhum tipo de empatia espiritual interna com seus informantes. Como qualquer um de nós eles também preferem considerar suas almas como suas [...].

A nossa concordância com a visão do autor de que para compreender a vida social é preciso "estabelecer uma conexão esclarecedora com os conceitos de experiência distante criados por teóricos" tem a ver com a simpatia que temos pela ideia de "corte epistemológico" entre senso comum e ciência de Gaston Bachelard, ${ }^{48}$ que estabelece a diferença ente essas duas formas de pensamento dizendo que, enquanto o senso comum vai do real para o teórico, a ciência vai do teórico para o real. Essa concordância não nos impede de estarmos longe de seu ultrarracionalismo. Não importa aqui que tanto o senso comum como o real sejam construídos; o que importa é que são construções diferentes. Não

${ }^{43}$ TORRES, 2009, p. 352

44 SCOTT, 1999.

${ }^{45}$ SCOTT, 1999, p. 27.

${ }^{46}$ GEERTZ, 2003.

${ }^{47}$ GEERTZ, 2003, p. 88.

${ }^{48}$ BACHELARD, 1974a; $1974 \mathrm{~b}$. 
defendemos a ideia de que, por aceitarmos que tanto a ciência, quanto o senso comum e a literatura são interpretações, essas formas de pensamento se equivalem. São interpretações baseadas em parâmetros diferentes e, na ciência, o que faz a diferença são as teorias com suas formas próprias de validação. Juntar tudo, igualar cada um desses ramos do conhecimento humano seria tão empobrecedor quanto separá-los rigidamente.

Por fim, Anthony Giddens ${ }^{49}$ reforça nossas convicções e as esclarece quando diz que a posição relativista começa com um postulado universal (tudo é relativo) e só termina com a descoberta de que todo conhecimento se move em círculo e, para ultrapassar o relativismo de julgamento, é necessário sustentar uma distinção entre sentido e referência em relação aos quadros de significância. Ele retoma a importância da teoria e a importância dos conceitos construídos pelo pesquisador (e não total submissão à fala dos entrevistados), dizendo que as ciências sociais podem empregar legitimamente conceitos que não são necessariamente familiares àqueles a cujo comportamento esses conceitos se referem..$^{50}$

\section{Considerações finais}

Fácil está perceber que a primeira parte deste artigo é mais investigativa e analíica, enquanto a segunda compõe-se de reflexões e dilemas pessoais. Se a mantivemos juntas é porque nossa experiência de professora, orientadora e militante vem mostrando que as dificuldades com que temos nos defrontado não são só nossas. Enquanto o feminismo tem uma marca urbana muito forte, a sociologia rural esteve sempre bem pouco atenta para as raízes machistas que se escondem sobre os conceitos de "família rural" e "trabalho familiar". Juntem-se a isso as correntes vindas da ecologia dos mais diferentes matizes e logo perceberemos que o ecofeminismo é um campo de forças que, apesar de ainda pouco conhecido por ser relativamente novo, tem muitos componentes para gerar tensão e embates. Se essa corrente do feminismo ainda não é tão forte no Brasil como o é em outros países, está se tornando cada vez mais visível. Mesmo quando há uma recusa de um dos termos, seja feminismo, seja ecologia, a prática de alguns grupos militantes tem mostrado que está havendo uma aproximação entre os dois maiores movimentos sociais surgidos no século $X X$, o feminista e o ecológico. Seria otimismo demais pensar que tal união poderá ser construída sem tensões e impasses, mas desistir dela seria um pessimismo a priori. Nós, mulheres, temos pressa, é verdade, pois as desigualdades nos oprimem há tantos séculos, mas se nossa militância não andar lado a lado com um grande esforço de compreensão, de reflexão e de diálogo, o pluralismo conquistado pelo feminismo pode se tornar apenas fragmentação, o que o coloca muito distante da multiplicidade.

\section{Referências bibliográficas}

ANGIONI, Lucas. "A filosofia da natureza de Aristóteles". Ciência \& Ambiente, n. 28, p. 5-15, jan./jun. 2004.

ARGAWAL, Bina. A field of one's own: gender and land rights in South Africa. New York: Cambridge University Press, 1994.

BACHELARD, Gaston. "A epistemologia não cartesiana". In: Abril, 1974a. p. 316-337.

\footnotetext{
49 GIDDENS, 1978.

${ }^{50}$ Não podemos concluir este artigo sem agradecer críticas e sugestões de ideias e textos feitas pelos colegas, todos professores doutores, Tâmara Benakouche, Maria Angela S. Paulilo (especialmente), Selvino J. Assmann, David J. Caume, Carlos E. Sell e Leila Christina D. Dias. Um texto que precisou de mais de dois anos para ser escrito só poderia ter como resultado algo um tanto fragmentado, repetitivo e com hiatos. Se os colegas não conseguiram dar conta de todas as deficiências, a responsabilidade é inteiramente nossa.
} 
BACHELARD, Gaston. 1974b. "A filosofia do não". In: Os pensadores. São Paulo: Abril, 1974b. p. 169-188, caps. 1 e 2.

BORDALO, Caroline A. Os caminhos da representação política: um estudo a partir dos movimentos de mulheres rurais. Trabalho apresentado no II Seminário Nacional Movimentos sociais, participação e democracia. Florianópolis, 25 a 27 de abril, 2007.

CARDOSO, Ruth C. L. "Aventuras de antropólogos em campo ou como escapar das armadilhas do método". In: CARDOSO, Ruth. C. L. (Org.). A aventura antropológica: teoria e pesquisa. Rio de Janeiro: Paz e Terra, 1986. p. 95-105.

FEMENÍAS, Maria Luisa; SPADARO, Maria Cristina. "Ecopasividad o ecofeminismo?" In: CAVANA, Maria Luísa; PULEO, Alicia H.; SEGURA, Cristina. (Coords). Mujeres y ecologia. Madrid: A.C. Al-Mudayna, 2004. p.233-241.

FERRY, Luc. Aprender a viver; filosofia para os novos tempos. Rio de Janeiro: Objetiva, 2007. GALLINA, Albertino L. "A concepção cartesiana da Natureza". Ciência \& Ambiente, n. 28, p. 29-40, jan./jun. 2004.

GEERTZ, Clifford. O saber local. Petrópolis: Vozes, 2003.

GIDDENS, Anthony. Novas regras do método sociológico. Rio de Janeiro: Zahar Editora, 2003.

HAMN, Christian. "Natureza em Kant”. Ciência \& Ambiente, n. 28, p. 41-52, jan./jun. 2004.

HELFAND, Steven M.; DEL GROSSI, Mauro E. Agricultural Boom and Rural Poverty in Brazil: An Exploratory Analisys of the 1995-2006 Period. Paper prepared for FAO as part of the project on "Agricultural Boom and Rural Poverty in Latin America", August 31. p. 59. Disponível em: <http://economics.ucr.edu/helfand CV 11-09.pdf. > Acesso em: 31 jan. 2009.

HOWARD, Patricia L. (ed.). Women and Plants: Gender Relations in Biodiversity Management \& Conservation. London \& New York: Zed Books, 2003.

KESSELRING, Thomas. "O conceito de Natureza na história do pensamento ocidental". Episteme/Grupo interdisciplinar em Filosofia e História das Ciências, n. 11, p. 153-172, jul./dez. 2000.

LE GOFF, Jacques; SCHMITT, Jean-Claude. Dicionário temático do Ocidente Medieval. v. II. Bauru-SP: Edusc, 2006. v. II.

LÓPEZ, Maricel M. "Entrevista com Ivone Gebara". In: GEBARA, Ivone. Epistemologia ecofeminista. Revista do Núcleo de Estudos Teológicos na América Latina "Ecofeminismo: Tendências e Debates". São Paulo: Ed. da Umesp, 2001.

MARIANO, Silvana A.; CARLOTO, Cássia M. "Gênero e combate à pobreza". Revista Estudos Feministas, v. 17, n. 3, p. 901-907, 2009.

MMC - MOVIMENTO DE MULHERES CAMPONESAS. Movimento de Mulheres Agricultoras: 21 anos de organização em Santa Catarina. Chapecó-SC: MMC, 2004.

ODENT, Michel. The Farmer and the Obstetrician. London: Free Association Books Ltda. 2002.

PAULILO, M. Ignez. "El Movimiento de Mujeres Campesinas y el médio ambiente". Otras Miradas: Revista Venezuelana de Estudios de Gênero, Universidade de Los Andes, Mérida, Venezuela, v. 7, n. 1, p.84-96, jan./jun. 2007.

RODRIGUES MAGDA, Rosa Maria. "El placer del simulacro: feminismo e transmodernidad". In: FEMENÍAS, Maria Luisa (Comp.). Perfiles del feminismo iberoamericano. Buenos Aires: Catálogos, 2007. v. 3. p. 139-160.

ROMANO, Roberto. "A mulher e a desrazão ocidental".In: Lux in tenebris: meditações sobre filosofia e cultura. São Paulo; Campinas: Cortez; Editora da Unicamp, 1987. p. 123-132. 
ROSSATTO, Noeli Dutra. "Natura naturans, natura naturata: o sistema do mundo medieval". Ciência \& Ambiente, n. 28, p. 17-28, jan./jun. 2004.

SCOTT, Joan W. "Experiência". In: SILVA, Alcione L. da; LAGO, Mara Coelho; RAMOS, Tânia O. (Orgs.). Falas de gênero. Florianópolis: Editora Mulheres, 1999. p. 21-55.

SELL, Carlos Eduardo. A virada mísitca: subsídios para uma análise sociológica do discurso místico da Teologia da Libertação. 2004. Tese (Doutorado em Sociologia) - Programa de Pós-Graduação em Socilogia, Universidade Federal de Santa Catarina, Florianópolis.

SHAAF, Alie van der. Jeito de mulher: a busca de direitos sociais e da igualdade de gênero no Rio Grande do Sul. Passo Fundo: UPF, 2001.

SHIVA, Vandana; MIES, Maria. Ecofeminismo. Lisboa: Instituto Piaget, 1997.

TORRES, Iraildes C. "Gênero e meio ambiente na Amazônia". In: TORNQUIST, Carmen S. et al. (Org.). Leituras de resistência: corpo, violência e poder. Florianópolis: Editora Mulheres, 2009. v. 2. p. 345-356.

ZERILLI, Linda M. G. El feminismo y el abismo de la libertad. Buenos Aires: Fondo de Cultura Econômica, 2008.

[Recebido em maio de 2010 e aceito para publicação em outubro de 2010]

\section{Intellectuals and Militants: Possibilities of Dialogue}

Abstract: The purpose of this article is to explain the concept of Nature that founds the ideas and actions of the Peasant Women's Movement, and to reflect on the possibilities of dialogue between militants and intellectuals. For this it must take into account that, while academic feminism is strongly influenced by the deconstructionist lines of thought, farming women sustain the idea, based on a deeply religious vision, of a natural identification between women and Nature. In pointing out possibilities for dialogue, the paper underlines the importance of lines of thought connected with the sociology of comprehension.

Key words: Peasant Women's Movement; Feminism; Gender; Family Farming. 